\title{
EXPERIÊNCIAS VIVENCIADAS NO ESTÁGIO SUPERVISIONADO I NO ENSINO DE CIÊNCIAS EM ESCOLAS DE ENSINO FUNDAMENTAL
}

\author{
Gabriela Silva de Aguiar ${ }^{1}$ \\ Vanusa Rosa Falqueto Fracarole ${ }^{2}$ \\ Glaucia Maria Ferrari ${ }^{3}$
}

\begin{abstract}
Resumo: De acordo com o parecer do Conselho Nacional de Educação (CNE) CNE/CP 28/2001, o estágio pode ser definido como um tempo de aprendizado que, alguém se demora em algum lugar ou ofício para aprender a prática do mesmo e depois poder exercer uma profissão ou ofício. O presente trabalho aborda experiências vivenciadas por alunos do curso de licenciatura em Ciências Biológicas do Instituto Federal de educação do Espírito Santo (Ifes) - Campus Alegre durante a disciplina de Estágio Supervisionado I. Os alunos da disciplina responderam a um questionário com questões abertas descrevendo informações sobre as experiências vivenciadas durante o estágio e sua importância para a formação no curso de licenciatura. Os resultados demonstraram a percepção dos alunos acerca da motivação e das principais dificuldades encontradas durante o estágio. Podendo assim concluir que o Estágio Supervisionado contribui para a formação inicial do professor de Ciências, caracterizando-se como um objeto de estudo, reflexão e construtor de identidade.
\end{abstract}

Palavras-chave: Ciências Biológicas; Ensino; Formação; Estágio.

\footnotetext{
1 Instituto Federal de Educação do Espírito Santo, Campus Alegre, Brasil. E-mail: gabriella.aguiar23@gmail.com. 2 Instituto Federal de Educação do Espírito Santo, Campus Alegre, Brasil. E-mail: vanusafracarole@hotmail.com. ${ }^{3}$ Instituto Federal de Educação do Espírito Santo, Campus Alegre, Brasil. E-mail: galucia@gmail.com.
} 